\title{
VEGF, apelin and HO-1 in diabetic patients with retinopathy: a correlation analysis
}

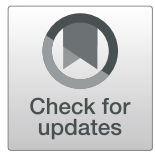

Rensiqin $\mathrm{Wu}^{\dagger}$, Zhifeng Zhu ${ }^{\dagger}$ and Dandan Zhou*

\begin{abstract}
Background: It's necessary to analyze the role of VEGF, apelin, and HO-1 in patients with type 2 diabetes (T2DM), and to evaluate its relevance to diabetic retinopathy (DR).

Methods: T2DM patients who were treated in our hospital from December 1, 2018 to November 30, 2019 were included. T2DM patients were divided into non-DR (NDR) group, non-proliferative DR (NPDR) group, and proliferative DR (PDR) group. and healthy participants were selected as the control group. The value of VEGF, apelin, and $\mathrm{HO} 1$ in predicting PDR were analyzed by receiver operating characteristic (ROC) curve, and the relations of VEGF, apelin, HO-1 and clinical factors in PDR patients were analyzed by Pearson correlation analysis.

Results: A total of 295 participants were included. The level of FPG and HbAlc in PDR group were significantly higher than that of other groups (all $p<0.05$ ); the level of VEGF and apelin in PDR group were significantly higher than that of other groups (all $p<0.05$ ), but the level of HO-1 in PDR group were significantly less than that of other groups $(p=$ 0.017); the AUC of VEGF, apelin, HO-1 and combined use was $0.806(95 \% \mathrm{Cl}: 0.779-0.861)$, $0.819(95 \% \mathrm{Cl}: 0.765-0.878)$, 0.808 (95\%Cl: $0.733-0.869)$ and $0.902(95 \% C l: 0.822-0.958)$ respectively, the AUC, sensitivity, specificity of the three combined use was significantly higher than that of single VEGF, apelin, HO-1 use(all $p<0.05)$. The cutoff values of serum VEGF, apelin, and HO-1 levels for predicting PDR were $163.85 \mathrm{pg} / \mathrm{ml}, 8.27 \mathrm{ng} / \mathrm{ml}$, and $26.06 \mathrm{mmol} / \mathrm{L}$ respectively. Serum VEGF, apelin, and HO-1 in patients with PDR was related to the time course of DM, FPG and HbAlc (all $p<0.05$ ).

Conclusions: VEGF, apelin and HO-1 are related to the progress of DR, and the combined use of VEGF, apelin and HO1 is beneficial to the diagnosis and treatment of PDR.
\end{abstract}

Keywords: Diabetic retinopathy, VEGF, Apelin, HO-1, Risks

\section{Background}

With the improvement of economic level, the aging related to the increase of average life expectancy, lifestyle has changed significantly changes such as sedentary and unbalanced diets [1]. Many of these factors have caused the number of patients with diabetes mellitus (DM) to increase year by year [2]. It is estimated that by 2025 , there will be 300 million people with diabetes worldwide, most of which will be in developing countries [3, 4]. Diabetic retinopathy (DR) is

\footnotetext{
*Correspondence: zhou21898@163.com

${ }^{\dagger}$ Rensigin Wu and Zhifeng Zhu contributed equally to this work. Department of Endocrinology, The Affiliated Hospital of Inner Mongolia Medical University, No.1st tunnel north road, Hohhot 010000, Innermongolia, China
}

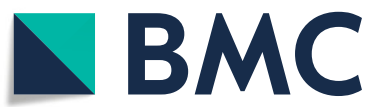

a common and serious complication of diabetes, and its incidence is closely related to the rising prevalence of diabetes [5]. For patients with the duration of diabetes more than 15 years, more than $80 \%$ patients will have DR [6]. It's been reported that the incidence of DR is 39\% in patients with type II diabetes who do not need insulin treatment, and the incidence of DR in patients with type II diabetes who require insulin is $70 \%[7,8]$. Proliferative diabetic retinopathy (PDR) is a middle-to-advanced DR, which is the main cause of severe visual impairment and even blindness [9]. The incidence of PDR increased from 0 to $25 \%$ during the course of $3-15$ years of diabetes $[10,11]$. Therefore, the prevention and treatment of PDR is essential to the prognosis of patients with diabetes.

(c) The Author(s). 2020 Open Access This article is licensed under a Creative Commons Attribution 4.0 International License, which permits use, sharing, adaptation, distribution and reproduction in any medium or format, as long as you give appropriate credit to the original author(s) and the source, provide a link to the Creative Commons licence, and indicate if changes were made. The images or other third party material in this article are included in the article's Creative Commons licence, unless indicated otherwise in a credit line to the material. If material is not included in the article's Creative Commons licence and your intended use is not permitted by statutory regulation or exceeds the permitted use, you will need to obtain permission directly from the copyright holder. To view a copy of this licence, visit http://creativecommons.org/licenses/by/4.0/ The Creative Commons Public Domain Dedication waiver (http://creativecommons.org/publicdomain/zero/1.0/) applies to the data made available in this article, unless otherwise stated in a credit line to the data. 
Table 1 The characteristics of included participants

\begin{tabular}{lllllll}
\hline Groups & Cases & Male/female & Age $(\mathrm{y})$ & Time course of DM(y) & BMl $\left(\mathrm{kg} / \mathrm{m}^{2}\right)$ & Hypertension $(\%)$ \\
\hline Control & 80 & $45 / 35$ & $57.9 \pm 3.95$ & - & $22.5 \pm 3.04$ & $22(27.5 \%)$ \\
NDR & 75 & $41 / 34$ & $57.4 \pm 2.57$ & $2.3 \pm 0.82$ & $22.2 \pm 2.99$ & $26(34.67 \%)$ \\
NPDR & 72 & $38 / 34$ & $56.9 \pm 3.88$ & $4.3 \pm 1.05$ & $22.5 \pm 3.13$ & $26(36.1 \%)$ \\
PDR & 68 & $37 / 29$ & $57.4 \pm 3.36$ & $7.2 \pm 2.44$ & $22.4 \pm 3.07$ & $24(35.29 \%)$ \\
$X^{2} / F$ & & 0.883 & 10.095 & 1.371 & 0.538 & 1.366 \\
$p$ & 0.114 & 0.098 & 0.021 & 0.185 & 0.052 \\
\hline
\end{tabular}

The main pathological changes of DR are retinal hemorrhage, exudation, microvascular dilatation and neovascularization, but the specific pathogenesis is not yet clear [6]. Recent studies have found that VEGF is involved in retinal exudation, bleeding, and retinal neovascularization, and its level changes have a certain correlation with the occurrence and development of DR [12-14]. Apelin is a new type of adipokine, it's also a kind of angiotensin receptor-related protein [15]. It's been reported that Apelin is involved in the proliferation of retinal endothelial cells and the angiogenesis process [16]. Furthermore, previous studies have reported that heme oxygenase 1 ( $\mathrm{HO}-$ 1) abnormally expressed in retinal cells cultured in high glucose and in the retina of diabetes animal models [17, 18]. It's well-proven that VEGF, apelin, HO-1 are related to many physiological and pathological processes related to immune response such as vascular homeostasis, cell proliferation and apoptosis, and inflammation, but its relationship with DR has not yet been clarified [19, 20]. It's necessary to further clarify the role of VEGF, apelin, and HO- 1 in patients with diabetes. Therefore, we attempted to conduct this study to elucidate the role of VEGF, apelin and HO-1 in diabetes II (T2DM) patients, to provide evidence for the prevention and treatment of DR.

\section{Methods}

\section{Ethical consideration}

Our study has been approved by the ethics committee of the Affiliated Hospital of Inner Mongolia Medical University (20181015), and written consents were obtained from all included patients.

\section{Participants}

T2DM patients who were treated in the department of endocrinology of our hospital from December 1, 2018 to November 30, 2019 were included. The inclusion criteria were as follows: (1) The diagnosis of T2DM met the DM diagnosis guidelines and classification standards [21-23];(2) The patient did not use cytotoxic agents and immunosuppressive drugs, and had no history of taking medication in the past 4 weeks, and had a normal white blood cell count;(3) The patient was informed and agreed to participate in this present study. The exclusion criteria were as follows: (1) Type $1 \mathrm{DM}$ and other types of DM; (2) patients with acute and chronic infections, liver and kidney disease, rheumatic connective tissue disease, cardio-cerebral vascular disease, and malignant tumors; (3) Patients with ocular diseases or fundus lesions that cannot be graded other than DR; (4) Patients who refuse to cooperate and follow up.

All included T2DM patients underwent vision, slitlamp microscope, indirect ophthalmoscope, and fundus fluorescein angiography (FFA) examination. With reference to the clinical diagnostic criteria of $D R$, the included T2DM patients were divided into nonDR (NDR) group, non-proliferative DR (NPDR) group, and proliferative DR (PDR) group based on the test results.

Additionally, healthy people who underwent physical examination in our hospital during the same period were selected as the control group. For this group, we exclude those with systemic and ocular diseases, and those with a body mass index $(\mathrm{BMI}) \geq 25 \mathrm{~kg} / \mathrm{m}^{2}$.

Table 2 The HDL-C, LDL-C, TG, TC, FPG, HbAlc level among groups

\begin{tabular}{llllllll}
\hline Groups & Cases & $\mathrm{HDL}-\mathrm{c}(\mathrm{mmol} / \mathrm{L})$ & $\mathrm{HDL}-\mathrm{c}(\mathrm{mmol} / \mathrm{L})$ & $\mathrm{TG}(\mathrm{mmol} / \mathrm{L})$ & $\mathrm{TC}(\mathrm{mmol} / \mathrm{L})$ & $\mathrm{FPG}(\mathrm{mmol} / \mathrm{L})$ & $\mathrm{HbAlc}(\%)$ \\
\hline Control & 80 & $2.37 \pm 0.22$ & $2.57 \pm 0.32$ & $1.58 \pm 0.21$ & $4.31 \pm 0.61$ & $5.29 \pm 0.97$ & $5.11 \pm 0.68$ \\
NDR & 75 & $2.36 \pm 0.30$ & $2.49 \pm 0.35$ & $1.59 \pm 0.28$ & $4.66 \pm 0.68$ & $6.02 \pm 1.33^{*}$ & $8.95 \pm 1.80^{*}$ \\
NPDR & 72 & $2.29 \pm 0.36$ & $2.50 \pm 0.41$ & $1.72 \pm 0.31$ & $5.03 \pm 0.84$ & $9.15 \pm 2.16^{* \#}$ & $9.84 \pm 2.15^{* \#}$ \\
PDR & 68 & $2.30 \pm 0.38$ & $2.44 \pm 0.35$ & $1.74 \pm 0.28$ & $5.79 \pm 0.78$ & $11.80 \pm 3.19^{* \# \&}$ & $10.17 \pm 3.32^{* \# \&}$ \\
F & & 1.395 & 0.988 & 0.852 & 1.096 & 10.468 & 9.395 \\
p & & 0.275 & 0.107 & 0.097 & 0.145 & 0.037 & 0.011 \\
\hline
\end{tabular}

Notes: ${ }^{*} p<0.05$ compared with Control; ${ }^{\#} p<0.05$ compared with NDR; ${ }^{\&} p<0.05$ compared with Control 
Table 3 The VEGF, apelin and HO-1 level among groups

\begin{tabular}{lllll}
\hline Groups & Cases & VEGF $(\mathrm{pg} / \mathrm{ml})$ & Apelin $(\mathrm{ng} / \mathrm{ml})$ & HO- $1(\mathrm{mmol} / \mathrm{L})$ \\
\hline Control & 80 & $57.03 \pm 9.49$ & $2.09 \pm 0.82$ & $50.38 \pm 9.15$ \\
NDR & 75 & $89.15 \pm 10.44^{*}$ & $4.22 \pm 1.04^{*}$ & $41.06 \pm 8.52^{*}$ \\
NPDR & 72 & $153.25 \pm 20.58^{* \#}$ & $6.58 \pm 1.86^{* \#}$ & $33.79 \pm 6.15^{* \#}$ \\
PDR & 68 & $186.50 \pm 30.16^{* \#}$ & $9.16 \pm 2.33^{* \#}$ & $25.19 \pm 5.27^{* \#}$ \\
F & & 28.573 & 20.805 & 16.187 \\
p & & 0.001 & 0.003 & 0.017 \\
\hline N $^{*}$ & &
\end{tabular}

Notes: ${ }^{*} p<0.05$ compared with Control; ${ }^{\#} p<0.05$ compared with NDR; ${ }^{\text {\& }} p<$ 0.05 compared with Control

\section{Laboratory analysis}

All participants have been taken $5 \mathrm{ml}$ of cubital vein blood on an status of empty stomach. After centrifugation, the serum was collected and stored in a $-70{ }^{\circ} \mathrm{C}$ refrigerator. ELISA was used to determine the level of serum VEGF, apelin, HO-1. The detection kit was purchased from Hensheng biomedicine company (Shanghai, China). all the operation was strictly performed in accordance with the manual instructions of related kits.

\section{Data collections}

We collected and recorded the participants' age, gender, duration of DM, blood pressure, height, weight, BMI, fasting blood glucose (FPG), glycated hemoglobin (HbAlc), total cholesterol (TC), triglycerides (TG), Total cholesterol (TC), high density lipoprotein cholesterol (HDL-c), low density lipoprotein cholesterol (LDL-c) and other laboratory indicators.

\section{Statistical analysis}

Statistical analysis was performed using SPSS 23.0 software. Measurement data are expressed as mean \pm standard deviation $(\mathrm{M} \pm \mathrm{SD})$. One-way analysis of variance was used for comparison between multiple groups, and SNK test was used for pairwise comparison within groups; Group t test was used for comparison between two groups. Chi-square test was used for comparison of count data. According to the receiver operating characteristic (ROC) curve, the thresholds for predicting the occurrence of PDR by VEGF, apelin, and HO-1 were determined. The determination of the critical values was based on the maximum Jordanian index (sensitivity + specificity-1). The area under the ROC curve (AUC) was used to compare the predictive value of related factors to the occurrence of PDR, and to determine its sensitivity and specificity, positive and negative predictive values. In this present study, AUC less than 0.8 was considered as low predicted value, a AUC within 0.8 to 0.9 was considered as medium predicted value, and AUC > 0.9 was considered as high predicted value. The correlation analyses on the serum VEGF, apelin, HO-1 with clinical indicators were conducted with Pearson correlation analysis methods. In this present study, $P<0.05$ was considered statistically significant.

\section{Results}

The characteristics of included participants

A total of 295 participants were included in this preset study, with 80 controls, 75 NDR patients, 72 NPDR patients and 68 PDR patients respectively (Table 1 ). There was significant difference in the time course of $\operatorname{DM}(p=$ 0.021) among DM groups, no significant differences were found in the gender, age, BMI and cases of hypertension among groups (all $p>0.05$ ).

\section{The HDL-c, LDL-c, TG, TC, FPG, HbAlc level}

As Table 2 presented, there were significant differences in the FPG, HbAlc level among groups, and the level of FPG and HbAlc in PDR group were significantly higher than that of other groups (all $p<0.05$ ), and no significant differences were found in the HDL-c, LDL-c, TG, TC level among groups (all $p>0.05$ ).
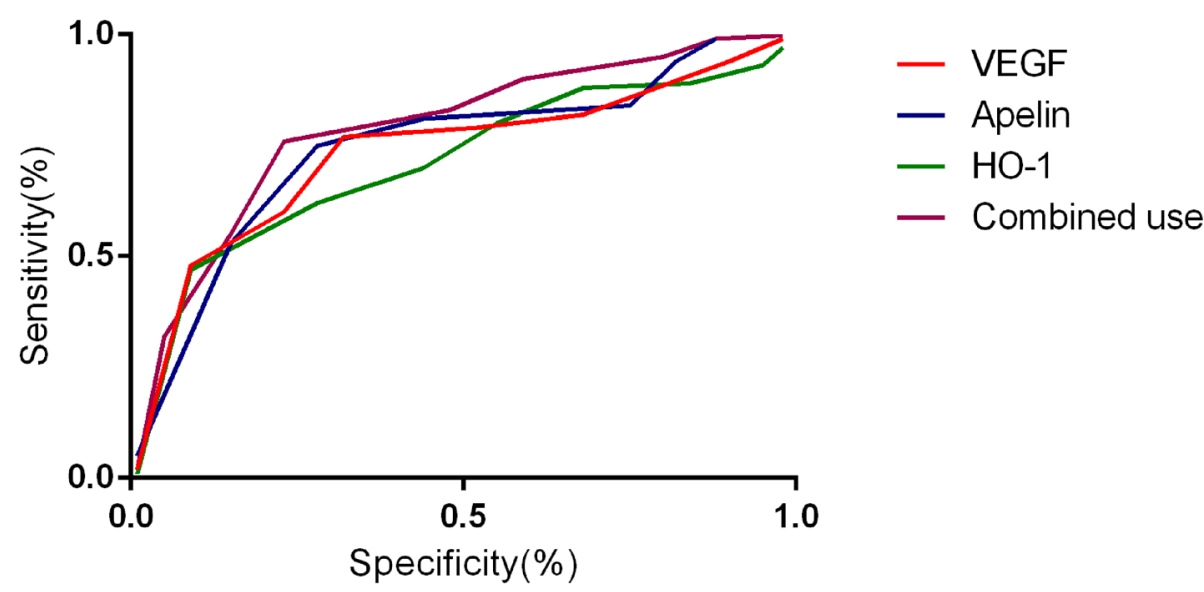

Fig. 1 The ROC curve of VEGF, apelin, $\mathrm{HO}^{-1}$ for predicating PDR 
Table 4 The analysis on the diagnosis value of VEGF, apelin, HO-1 for PDR

\begin{tabular}{lllllllll}
\hline Items & Cutoff & AUC & $95 \% \mathrm{Cl}$ & $\mathrm{p}$ & Sensitivity(\%) & Specificity(\%) & Positive predictive value(\%) & Negative predictive value(\%) \\
\hline VEGF & 163.85 & 0.806 & $0.779-0.861$ & 0.021 & 76.43 & 85.19 & 88.42 & 71.90 \\
Apelin & 8.27 & 0.819 & $0.765-0.878$ & 0.016 & 84.08 & 82.95 & 85.68 & 80.62 \\
HO-1 & 26.06 & 0.798 & $0.733-0.829$ & 0.009 & 73.99 & 81.42 & 78.15 & 78.07 \\
Combined use & - & 0.885 & $0.812-0.918$ & 0.007 & 90.35 & 83.18 & 86.69 & 85.23 \\
\hline
\end{tabular}

\section{The VEGF, apelin and HO-1 level}

As Table 3 presented, there were significant differences in the VEGF, apelin and HO-1 level among groups, and the level of VEGF and apelin in PDR group were significantly higher than that of other groups (all $p<0.05$ ), but the level of HO-1 in PDR group were significantly less than that of other $\operatorname{groups}(p=0.017)$.

\section{The diagnosis value of VEGF, apelin, HO-1 for PDR}

As Fig. 1 and Table 4 showed, the AUC of VEGF, apelin, HO- 1 and combined use was 0.806(95\%CI: 0.779-0.861), 0.819(95\%CI: $0.765-0.878), \quad 0.808(95 \% \mathrm{CI}: \quad 0.733-0.869)$ and $0.902(95 \% \mathrm{CI}: 0.822-0.958)$ respectively, the AUC, sensitivity, specificity of the three combined use was significantly higher than that of single VEGF, apelin, HO-1 use(all $p<0.05)$. The cutoff values of serum VEGF, apelin, and HO-1 levels for predicting PDR were $163.85 \mathrm{pg} /$ $\mathrm{ml}, 8.27 \mathrm{ng} / \mathrm{ml}$, and $26.06 \mathrm{mmol} / \mathrm{L}$ respectively.

\section{The risk factors related to PDR}

As Table 5 presented, Pearson correlation analysis showed that serum VEGF, apelin, and $\mathrm{HO}-1$ in patients with PDR was related to the time course of DM, FPG and HbAlc (all $p<0.05$ ), and the serum VEGF, apelin, and $\mathrm{HO}-1$ in patients with PDR was not related to the age, gender, BMI, hypertension, HDL-c, LDL-c, TG and

Table 5 Correlation analysis on the risk factors related to PDR

\begin{tabular}{|c|c|c|c|c|c|c|}
\hline \multirow[t]{2}{*}{ Variables } & \multicolumn{2}{|l|}{ VEGF } & \multicolumn{2}{|l|}{ Apelin } & \multicolumn{2}{|l|}{$\mathrm{HO}-1$} \\
\hline & $r$ & $p$ & $r$ & $p$ & $r$ & $p$ \\
\hline Age & 0.215 & 0.180 & 0.257 & 0.097 & -0.148 & 0.103 \\
\hline Gender & 0.115 & 0.097 & 0.150 & 0.104 & -0.121 & 0.079 \\
\hline Time course of DM & 0.389 & 0.042 & 0.275 & 0.033 & 0.206 & 0.044 \\
\hline BMI & 0.167 & 0.079 & 0.201 & 0.059 & 0.085 & 0.102 \\
\hline Hypertension & 0.294 & 0.157 & 0.175 & 0.202 & 0.213 & 0.119 \\
\hline $\mathrm{HDL}-\mathrm{C}$ & -0.168 & 0.096 & -0.074 & 0.138 & 0.128 & 0.085 \\
\hline LDL-C & 0.156 & 0.104 & 0.183 & 0.099 & -0.226 & 0.142 \\
\hline TG & 0.115 & 0.095 & 0.245 & 0.206 & -0.117 & 0.195 \\
\hline $\mathrm{TC}$ & 0.099 & 0.183 & 0.105 & 0.126 & -0.136 & 0.092 \\
\hline $\mathrm{FPG}$ & 0.468 & 0.018 & 0.381 & 0.009 & -0.403 & 0.017 \\
\hline HbAlc & 0.395 & 0.037 & 0.214 & 0.015 & -0.378 & 0.035 \\
\hline VEGF & - & - & 0.787 & 0.011 & -6.165 & 0.017 \\
\hline Apelin & 0.787 & 0.011 & - & - & -5.090 & 0.009 \\
\hline
\end{tabular}

TC (all $p>0.05)$. Serum VEGF, apelin and HO-1 were significantly correlated with each other $(r=0.787$, $6.165,-5.090$ respectively, all $p<0.05)$.

\section{Discussion}

Retinal microvessels are exposed to high glucose and hypoxic environments for a long time in DM patients, and retinal sensory nerve function damage, and the changes in microvascular structure and function will occur, leading to the onset and development of DR [24]. With the progress of the disease, the retinal microvessels gradually developed from early aneurysm-like changes to the formation of new blood vessels. The walls of newly generated microvessels are fragile and lack the oxygen supply. It is easy to rupture under the action of pulling, causing severe consequences such as vitreous hemorrhage and retinal detachment, and it can eventually lead to blindness without effective clinical intervention $[14,25]$. Therefore, the early diagnosis and treatment of PDR are very important to the prognosis of DM patients. The results of this present study have revealed that VEGF, apelin, and HO-1 are associated with the development of PDR, and they can be adopted for the diagnosis of PDR with consideration to their good predicating value.

VEGF is a kind of dimeric glycoprotein with heparinbinding activity, and its main role is to promote the proliferation of endothelial cells and induce the formation of new blood vessels [26, 27]. The blood supply to the retina plays an important role in maintaining and protecting the functions of retinal ganglion cells. VEGF can specifically bind to vascular endothelial cell receptors, increase the permeability of blood vessels, aggravate ischemia and hypoxia in local retinal tissues [28]. Previous study has pointed out that there is no correlation between the expression levels of VEGF in blood and vitreous fluid in patients with PDR, and he believes that almost all VEGF in vitreous fluid is generated by the surrounding tissues in the eye [29]. But the study by Baharivand et al. has shown a positive correlation between VGEF levels in blood and vitreous fluid $(r=0.45)$ [30]. The results of our study have further indicated that VGEF is associated with the development of PDR.

As a fat cytokine, Apelin plays an important role in various pathophysiological processes such as inflammatory response, immune response, cell growth and 
development, and apoptosis [16, 31]. Recent studies have found that apelin can stimulate retinal endothelial cell proliferation and retinal neovascularization [32-34]. And previous studies have found that apelin receptor is highly expressed in the formation of embryonic blood vessels and the formation of retinal blood vessels in mice $[35,36]$. The link between the high expression of this receptor and angiogenesis is closely related to the mitogenic properties of apelin on endothelial cells and the activation of new blood vessels [37]. In the experiments using retinal vascular endothelial cell line RF/6A in vitro, Kasai et al. have found that apelin can significantly promote the proliferation, migration and formation of vascular lumen of RF/6A cells [38]. The process of neovascularization depends on the proliferation and migration of vascular endothelial cells and the formation of capillary-like lumens [39], it is considered that apelin is a new angiogenic factor that has a mitogenic effect on endothelial cells and promotes angiogenesis.

HO-1 is a rate-limiting enzyme with anti-oxidant, antiinflammatory, anti-apoptotic effects [40]. When cells are stimulated by oxidative stress, oxidized low-density lipoprotein, cytokines and growth factors, and endotoxin, the activity of HO-1 can increase up to 100 times [41]. HO-1 is abundant in the retina, and is found in retinal pigment epithelial cells, microglia and neurons [42]. HO-1 decomposes free heme to bilirubin, ferritin and other antioxidant products, which together form an important endogenous protection system of the body [41]. Through multiple mechanisms such as anti-oxidation, anti-inflammatory damage, regulation of apoptosis and anti-proliferation, HO-1 helps the body's tissues and organs return to normal homeostasis after various pathological mechanisms are triggered. Previous studies have shown that HO-1 has certain effects on the development of DR [43, 44], especially on dysfunction and death of retinal endothelial cells, which is consistent with our findings.

\section{Conclusion}

The results of this study have indicated that there may be a close relationship between VEGF, apelin, HO-1 and abnormal glucose metabolism, and they may participate in the process of PDR. Previous studies have suggested that serum apelin levels are significantly increased in patients with DR, and it are related to patients with DM, which can be used as a reliable indicator for assessing the progress of DR $[45,46]$. It can be seen that the serum levels of VEGF and apelin are high in DR patients, while the expression level of HO-1 is lower. At the same time, the combined detection of VEGF, apelin and HO-1 is helpful to predict the development of PDR. However, limited by sample size, we cannot perform subgroup analysis based on different DR staging, more studies are needed to further explore the role of VEGF、 apelin and HO-1 and potential mechanisms in DM.

\section{Abbreviations}

DM: Diabetes mellitus; DR: Diabetic retinopathy; PDR: Proliferative diabetic retinopathy; NDR: Non-diabetic retinopathy; NPDR: Non-proliferative diabetic retinopathy; ROC: Receiver operating characteristic

\section{Acknowledgments \\ None.}

Authors' contributions

R W and D Z designed research; R W, Z Z and D Z conducted research; R W, $Z Z$ analyzed data; $R$ W wrote the first draft of manuscript; $R$ W and $D Z$ had primary responsibility for final content. All authors read and approved the final manuscript.

Funding

None.

Availability of data and materials

All data generated or analyzed during this study are included in this published article.

\section{Ethics approval and consent to participate}

Our study has been approved by the ethics committee of the Affiliated Hospital of Inner Mongolia Medical University (20181015), and written consents were obtained from all included patients.

\section{Consent for publication}

Not applicable.

\section{Competing interests}

The authors declare that they have no competing interests.

Received: 2 March 2020 Accepted: 1 June 2020

Published online: 08 August 2020

\section{References}

1. Schmidt AM. Diabetes mellitus and cardiovascular disease. Arterioscler Thromb Vasc Biol. 2019;39(4):558-68.

2. Rami-Merhar B, Frohlich-Reiterer E, Hofer SE. Diabetes mellitus in childhood and adolescence (update 2019). Wien Klin Wochenschr. 2019;131(Suppl 1): 85-90.

3. Martinez LC, Sherling D, Holley A. The screening and prevention of diabetes mellitus. Prim Care. 2019;46(1):41-52.

4. Glovaci D, Fan W, Wong ND. Epidemiology of diabetes mellitus and cardiovascular disease. Curr Cardiol Rep. 2019;21(4):21.

5. Pivari F, Mingione A, Brasacchio C, Soldati L. Curcumin and type 2 diabetes mellitus: prevention and treatment. Nutrients. 2019;11(8):8-16.

6. Singh RP, Elman MJ, Singh SK, Fung AE, Stoilov I. Advances in the treatment of diabetic retinopathy. J Diabetes Complicat. 2019;33(12):107417.

7. Semeraro F, Morescalchi F, Cancarini A, Russo A, Rezzola S, Costagliola C. Diabetic retinopathy, a vascular and inflammatory disease: therapeutic implications. Diabetes Metab. 2019;45(6):517-27.

8. Honasoge A, Nudleman E, Smith M, Rajagopal R. Emerging insights and interventions for diabetic retinopathy. Curr Diab Rep. 2019;19(10):100.

9. Sivaprasad S, Pearce E. The unmet need for better risk stratification of nonproliferative diabetic retinopathy. Diabet Med. 2019;36(4):424-33.

10. Aouiss A, Anka Idrissi D, Kabine M, Zaid Y. Update of inflammatory proliferative retinopathy: ischemia, hypoxia and angiogenesis. Curr Res Transl Med. 2019;67(2):62-71.

11. Yang QH, Zhang Y, Zhang XM, Li XR. Prevalence of diabetic retinopathy, proliferative diabetic retinopathy and non-proliferative diabetic retinopathy in Asian T2DM patients: a systematic review and meta-analysis. Int J Ophthalmol. 2019;12(2):302-11.

12. Rodriguez ML, Perez S, Mena-Molla S, Desco MC, Ortega AL. Oxidative stress and microvascular alterations in diabetic retinopathy: future therapies. Oxidative Med Cell Longev. 2019;2019:4940825.

13. Berrocal MH, Acaba LA, Chenworth ML. Surgical innovations in the treatment of diabetic macular edema and diabetic retinopathy. Curr Diab Rep. 2019;19(10):106. 
14. Zhou Z, Ju H, Sun M, Chen $H$. Serum vascular endothelial growth factor levels correlate with severity of retinopathy in diabetic patients: a systematic review and meta-analysis. Dis Markers. 2019;2019:9401628.

15. Dayem S, Battah AA, Bohy A, Yousef RN, Ahmed AM, Talaat AA. Apelin, nitric oxide and vascular affection in adolescent type 1 diabetic patients. Open Access Maced J Med Sci. 2017;5(7):934-9.

16. Soualmia H, Midani F, Hadj-Fradj S, Saadi N, Lassoued M, Messoud T, Gharbi M, Ben-Amor Z. The A445C variant in Apelin receptor and diabetic retinopathy in Tunisian patients. Clin Lab. 2017;63(2):379-83.

17. Abu El-Asrar AM, Mohammad G, Allegaert E, Ahmad A, Siddiquei MM, Alam K, Gikandi PW, De Hertogh G, Opdenakker G. Matrix metalloproteinase-14 is a biomarker of angiogenic activity in proliferative diabetic retinopathy. Mol Vis. 2018:24:394-406.

18. Gajos-Draus A, Duda M, Beresewicz A. Cardiac and renal upregulation of Nox2 and NF-kappaB and repression of Nox4 and Nrf2 in season- and diabetes-mediated models of vascular oxidative stress in guinea-pig and rat. Physiol Rep. 2017;5(20):14-9.

19. Praidou A, Androudi S, Brazitikos P, Karakiulakis G, Papakonstantinou E, Dimitrakos S. Angiogenic growth factors and their inhibitors in diabetic retinopathy. Curr Diabetes Rev. 2010;6(5):304-12.

20. Malik TG, Ahmed SS, Gul R, Khalil M, Malik AA, Khan M. Effect of intravitreal bevacizumab on macular thickness: exploring serum and vitreous proangiogenic biomarkers in patients with diabetic macular edema. Turk J Med Sci. 2018;48(4):833-9.

21. Lindholm E, Agardh E, Tuomi T, Groop L, Agardh CD. Classifying diabetes according to the new WHO clinical stages. Eur J Epidemiol. 2001;17(11):983-9.

22. Robertson GL. Diabetes insipidus: differential diagnosis and management. Best Pract Res Clin Endocrinol Metab. 2016;30(2):205-18.

23. Radda S, Bolz M, Egger S, Gasser-Steiner V, Kralinger M, Mennel S, Scholda C, Stolba U, Wedrich A. Die Netzhautkommission der osterreichischen ophthalmologischen G: [diagnosis, treatment and monitoring of diabetic eye disease (update 2019)]. Wien Klin Wochenschr. 2019;131(Suppl 1):164-8.

24. Lim RR, Wieser ME, Ganga RR, Barathi VA, Lakshminarayanan R, Mohan RR, Hainsworth DP, Chaurasia SS. NOD-like receptors in the eye: uncovering its role in diabetic retinopathy. Int J Mol Sci. 2020;21(3):1-7.

25. Shosha E, Fouda AY, Narayanan SP, Caldwell RW, Caldwell RB. Is the arginase pathway a novel therapeutic avenue for diabetic retinopathy? J Clin Med. 2020;9(2):33-40.

26. Wong TY, Cheung CM, Larsen M, Sharma S, Simo R. Diabetic retinopathy. Nat Rev Dis Primers. 2016:2:16012.

27. Wang W, ACY L. Diabetic retinopathy: pathophysiology and treatments. Int J Mol Sci. 2018;19(6):2-8

28. Terasaki H, Ogura Y, Kitano S, Sakamoto T, Murata T, Hirakata A, Ishibashi T. Management of diabetic macular edema in Japan: a review and expert opinion. Jpn J Ophthalmol. 2018;62(1):1-23.

29. Burgos R, Simo R, Audi L, Mateo C, Mesa J, Garcia-Ramirez M, Carrascosa A Vitreous levels of vascular endothelial growth factor are not influenced by its serum concentrations in diabetic retinopathy. Diabetologia. 1997;40(9): 1107-9.

30. Baharivand N, Zarghami N, Panahi F, Dokht Ghafari MY, Mahdavi Fard A, Mohajeri A. Relationship between vitreous and serum vascular endothelial growth factor levels, control of diabetes and microalbuminuria in proliferative diabetic retinopathy. Clin Ophthalmol. 2012;6:185-91.

31. Chen H, Liu C, Cheng C, Zheng L, Huang K. Effects of Apelin peptides on diabetic complications. Curr Protein Pept Sci. 2018;19(2):179-89.

32. Li Y, Bai YJ, Jiang YR, Yu WZ, Shi X, Chen L, Feng J, Sun GB. Apelin-13 is an early promoter of cytoskeleton and tight junction in diabetic macular edema via PI-3KJAkt and MAPKJErk signaling pathways. Biomed Res Int. 2018;2018:3242574.

33. Yasir M, Senthilkumar GP, Jayashree K, Ramesh Babu K, Vadivelan M, Palanivel C. Association of serum omentin-1, apelin and chemerin concentrations with the presence and severity of diabetic retinopathy in type 2 diabetes mellitus patients. Arch Physiol Biochem. 2019:1-8.

34. Lu Q, Ma Y, Xu YS, Jiang YR. Apelin in epiretinal membranes of patients with proliferative diabetic retinopathy. Mol Vis. 2014;20:1122-31.

35. Yonem A, Duran C, Unal M, Ipcioglu OM, Ozcan O. Plasma apelin and asymmetric dimethylarginine levels in type 2 diabetic patients with diabetic retinopathy. Diabetes Res Clin Pract. 2009;84(3):219-23.

36. Du JH, Li X, Li R, Xu L, Ma RR, Liu SF, Zhang Z, Sun HZ. Elevation of serum apelin-13 associated with proliferative diabetic retinopathy in type 2 diabetic patients. Int J Ophthalmol. 2014;7(6):968-73.
37. Tao Y, Lu Q, Jiang YR, Qian J, Wang JY, Gao L, Jonas JB. Apelin in plasma and vitreous and in fibrovascular retinal membranes of patients with proliferative diabetic retinopathy. Invest Ophthalmol Vis Sci. 2010;51(8): 4237-42.

38. Kasai A, Shintani N, Oda M, Kakuda M, Hashimoto H, Matsuda T, Hinuma S, Baba A. Apelin is a novel angiogenic factor in retinal endothelial cells. Biochem Biophys Res Commun. 2004;325(2):395-400.

39. Qian J, Lu Q, Tao Y, Jiang YR. Vitreous and plasma concentrations of apelin and vascular endothelial growth factor after intravitreal bevacizumab in eyes with proliferative diabetic retinopathy. Retina. 2011;31(1):161-8.

40. Castilho A, Aveleira CA, Leal EC, Simoes NF, Fernandes CR, Meirinhos Rl, Baptista Fl, Ambrosio AF. Heme oxygenase-1 protects retinal endothelial cells against high glucose- and oxidative/nitrosative stress-induced toxicity. PLoS One. 2012;7(8):e42428.

41. He M, Pan H, Xiao C, Pu M. Roles for redox signaling by NADPH oxidase in hyperglycemia-induced heme oxygenase- 1 expression in the diabetic retina. Invest Ophthalmol Vis Sci. 2013;54(6):4092-101.

42. Grochot-Przeczek A, Dulak J, Jozkowicz A. Heme oxygenase-1 in neovascularisation: a diabetic perspective. Thromb Haemost. 2010;104(3): 424-31.

43. Fan J, Xu G, Jiang T, Qin Y. Pharmacologic induction of heme oxygenase-1 plays a protective role in diabetic retinopathy in rats. Invest Ophthalmol Vis Sci. 2012;53(10):6541-56

44. Bucolo C, Drago F, Maisto R, Romano GL, D'Agata V, Maugeri G, Giunta S. Curcumin prevents high glucose damage in retinal pigment epithelial cells through ERK1/2-mediated activation of the Nrf2/HO-1 pathway. J Cell Physiol. 2019;234(10):17295-304.

45. Shibagaki F, Ishimaru Y, Sumino A, Yamamuro A, Yoshioka Y, Maeda S. Systemic Administration of an Apelin Receptor Agonist Prevents NMDAinduced loss of retinal neuronal cells in mice. Neurochem Res. 2020.

46. McAnally D, Siddiquee K, Gomaa A, Szabo A, Vasile S, Maloney PR, Divlianska DB, Peddibhotla S, Morfa CJ, Hershberger P, et al. Repurposing antimalarial aminoquinolines and related compounds for treatment of retinal neovascularization. PLoS One. 2018;13(9):e0202436.

\section{Publisher's Note}

Springer Nature remains neutral with regard to jurisdictional claims in published maps and institutional affiliations.
Ready to submit your research? Choose BMC and benefit from:

- fast, convenient online submission

- thorough peer review by experienced researchers in your field

- rapid publication on acceptance

- support for research data, including large and complex data types

- gold Open Access which fosters wider collaboration and increased citations

- maximum visibility for your research: over $100 \mathrm{M}$ website views per year

At $\mathrm{BMC}$, research is always in progress.

Learn more biomedcentral.com/submissions 